\title{
DESENVOLVIMENTO DE CALOS EM EXPLANTES DE CUPUAÇUZEIRO (Theobroma grandiflorum Schum.) EM FUNÇÃO DA CONCENTRAÇÃO DE AUXINAS E DO MEIO LÍQUIDO ${ }^{1}$
}

\author{
MARIA DAS GRAÇAS RODRIGUES FERREIRA², FERNANDO ENRIQUE NINAMANGO CÁRDENAS³ \\ CARLOS HENRIQUE SIQUEIRA DE CARVALHO ${ }^{4}$, ANDRÉA ALMEIDA CARNEIRO ${ }^{5}$ e \\ CARLOS FERREIRA DAMIÃO FILHO ${ }^{6}$
}

\begin{abstract}
RESUMO - Objetivou-se estudar o efeito da concentração de auxina e do meio líquido sobre o desenvolvimento de calos de cupuaçuzeiro. Segmentos de eixos embrionários e cotilédones, obtidos de frutos de cupuaçu dos tipos Mamorana e Redondo, foram cultivados em 4 meios de cultura diferentes: 1) meio MS (50\%), suplementado com 2,4-D (1;2;4;8 mg/L);2) sais N6 (SIGMA) (4 g/L), acrescidos de 2,4-D $(0 ; 2 ; 4 \mathrm{mg} / \mathrm{L})$ e ANA $(0 ; 3 ; 5 \mathrm{mg} / \mathrm{L}) ; 3)$ igual ao anterior, suplementado apenas com ANA $(3 \mathrm{mg} / \mathrm{L}) ; \mathrm{e} 4)$ meio MS, acrescido com ANA (1 mM). Calos com aspecto branco e brilhante foram observados em segmentos de eixos embrionários e cotilédones, cultivados nas menores concentrações de meio 1 ( 1 e $2 \mathrm{mg} / \mathrm{L}$ ), enquanto nas maiores concentrações $(4$ e $8 \mathrm{mg} / \mathrm{L}$ ) se observou a formação de calos e massa calosa branco-opaca, em eixos embrionários e em segmentos cotiledonares, estas estruturas tornaram-se escuras dentro de oito semanas. Usando o meio 2, um grande número de raízes foram formadas, enquanto o mesmo meio suplementado apenas com ANA (3; $5 \mathrm{mg} / \mathrm{L}$ ) originou uma massa calosa. A combinação de ANA e 2,4-D, 3 e $2 \mathrm{mg} / \mathrm{L}$, respectivamente, promoveu a formação de calos brancos e raízes. A transferência das culturas para meio líquido, sem regulador de crescimento, promoveu aumento de tamanho dos explantes e escurecimento dos mesmos. O cultivo desses explantes no meio 3 resultou no aparecimento de calos amarelos, com aspecto friável, que permaneceram com a mesma aparência no meio 4.
\end{abstract}

Termos para indexação: cultura de tecidos, calos, auxina, Theobroma grandiflorum.

\section{DEVELOPMENT OF CUPUASSU CALLI (Theobroma grandiflorum Schum. ) IN FUNTION OF AUXIN CONCENTRATION AND LIQUID MEDIUM}

\begin{abstract}
It was studied the effect of auxin concentration and liquid medium on the development of cupuassu calli. Cupuassu embryonic axes segments and cotyledons, from kinds Mamorana and Redondo, were cultivated in four different culture media : 1) MS medium (50\%) supplemented with 2,4-D $(1 ; 2 ; 4 ; 8 \mathrm{mg} / \mathrm{L}) ; 2) \mathrm{N} 6$ salts (SIGMA) $(4 \mathrm{~g} / \mathrm{L})$ supplemented with 2,4-D $(0 ; 2 ; 4 \mathrm{mg} / \mathrm{L})$ and NAA $(0 ; 3 ; 5 \mathrm{mg} / \mathrm{L}) ; 3)$ similar to the previous medium supplemented only with NAA (3 mg/L) and, 4) MS medium, supplemented with NAA $(1 \mathrm{mM})$. Calli with white and bright aspect were observed in embryonic axes and cotyledons, cultivated in the smallest concentrations of medium 1 ( 1 and $2 \mathrm{mg} / \mathrm{L})$, while in the largest concentrations $(4$ and $8 \mathrm{mg} / \mathrm{L}$ ) opaque white calli and calli mass were formed in embryonic axes and in cotyledons segments, these structures became brownish within eight weeks. Using medium 2, a great number of roots were formed, while this same medium supplemented only with NAA $(3 ; 5 \mathrm{mg} / \mathrm{L})$ originated a calli mass. . The presence of NAA and 2,4-D, 3 and $2 \mathrm{mg} / \mathrm{L}$ respectively, promoted the formation of white calli and roots. The transfer of the explants to liquid medium, without growth regulator, promoted an increase of explants size and browning of them. The cultivation of those explants in medium 3 resulted in the formation of yellow calli, with friable aspect, that kept the same aspect in medium 4.
\end{abstract}

Index terms: tissue culture, calli, auxin, Theobroma grandiflorum

\section{INTRODUÇÃo}

O cupuaçuzeiro (Theobroma grandiflorum) é uma árvore frutífera, tipicamente amazônica, pertencente à família das Sterculiaceas, que se encontra disseminada por toda a bacia Amazônica, sendo esporadicamente encontrada em outros países como a Colômbia, Venezuela, Equador e Costa Rica (Venturieri et al., 1985).

O maior valor da espécie está na polpa, que se encontra aderida às sementes, é de cor branco-amarelada, sabor ácido e cheiro agradável característico, sendo utilizada in natura ou na fabricação de néctar enlatado, sorvetes, licores, compotas,

1 (Trabalho 025/2001). Recebido: 23/01/2001. Aceito para publicação: 31/07/2001. Parte da Tese de Doutorado apresentada pelo primeiro autor à FCAVJ/UNESP, Campus de Jaboticabal, para obtenção do título de Doutor em Agronomia, área de concentração em Produção Vegetal.

2 Eng. Agrôn., Dr., Bolsista Recém-Doutor, CENA/USP, Laboratório de Biotecnologia Vegetal, Av. Centenário, 303, Cx Postal 96. CEP - 13400-970, Piracicaba-SP.E-mail:mgrf23@hotmail.com

3 Eng. Agrôn., Doutorando em Genética e Melhoramento de Plantas, ESALQ/USP, Av. Pádua Dias, CEP - 13400-970, Piracicaba-SP.

4 Eng. Agrôn., Ph D., Embrapa Milho e Sorgo, Cx. Postal 151, Sete Lagoas, MG, CEP - 35701-970.

5 Biól., Ph. D., Embrapa Milho e Sorgo, Cx. Postal 151, Sete Lagoas, MG, CEP - 35701-970.

6 Prof. Dr., Depto. de Biologia Aplicada à Agropecuária, FCAV-UNESP, Via de Acesso Prof. Paulo Donato Castellane, Km 05, Jaboticabal, SP, CEP- 14870-000. 
geléias, iogurtes, etc (Calzavara et al., 1984; Venturieri et al., 1985).

Certas espécies de plantas são recalcitrantes à obtenção de calos em quaisquer tipos de explantes, sendo que algumas gramíneas e muitas espécies lenhosas só produzem calos quando são empregadas doses altíssimas de auxinas no meio de cultura (Damião Filho, 1995).

Singha (1982) observou aumento da disponibilidade e absorção de nutrientes pelos explantes, quando estes foram colocados em meios líquido e semi-sólido. Pierik (1987) afirmou que os melhores resultados obtidos nestes meios devem-se à maior facilidade de absorção de nutrientes e reguladores de crescimento, e também devido ao maior contato entre explante e meio, ao contrário de meios mais sólidos, onde há somente contato basal. Os meios líquidos também permitem melhor diluição de exsudatos oriundos do explante, evitando, desta forma, o acúmulo de compostos tóxicos.

A literatura cita escassas contribuições à cultura do cupuaçuzeiro com aplicações de técnicas biotecnológicas. Janick \& Whipkey (1988) obtiveram embriões somáticos de cupuaçu, a partir de calos, contudo não conseguiram plântulas viáveis. É necessário incrementar as pesquisas básicas com esta valiosa espécie do gênero Theobroma. Assim, este trabalho teve como objetivo estudar o efeito da concentração de auxina e do meio líquido sobre o desenvolvimento de calos de cupuaçu.

\section{MATERIAL E MÉTODOS}

Os experimentos foram conduzidos no Laboratório de Biologia Celular do Núcleo de Biologia Aplicada, pertencente à Embrapa Milho e Sorgo, Sete Lagoas-MG.

Foram utilizados como fonte de explantes, eixos embrionários e cotilédones, obtidos de sementes de frutos imaturos de cupuaçu dos tipos Mamorana e Redondo. O material foi adquirido junto ao Centro de Pesquisa da Lavoura Cacaueira (CEPLAC), Itabuna, Bahia.

As sementes foram imersas em solução de $20 \%$ de hipoclorito de sódio, contendo 1 a 1,5\% de cloro ativo (alvejante comercial), durante 10 minutos, seguindo-se três lavagens com água bidestilada. Em condições de câmara asséptica, com o auxílio de bisturi, foram retirados os eixos embrionários das sementes e divididos em três partes: região da plúmula, radícula e hipocótilo. Os cotilédones foram segmentados em pedaços de 1,0 $-1,5 \mathrm{~cm}$. A seguir, esses explantes foram esterilizados com solução Ao (antioxidante), contendo $10 \mathrm{ml}$ de solução Ao - composta de ácido ascórbico (15 mg/L), cisteína (40 mg/L) e $\operatorname{AgNO}_{3}(2 \mathrm{mg} / \mathrm{L})$ - $30 \mathrm{ml}$ de alvejante comercial, $60 \mathrm{ml}$ de água destilada e 3 gotas de Tween 20. Os explantes ficaram imersos nesta solução por 1 hora e, posteriormente, foram imersos em solução de $9 \mathrm{ml} \mathrm{LS}$ (sais e vitaminas MS) $+1 \mathrm{ml}$ de Ao por dez minutos.

Os explantes foram cultivados em placas de Petri descartáveis $(90 \times 15 \mathrm{~cm})$ e as culturas mantidas em sala de crescimento, com temperatura variando entre $24^{\circ} \mathrm{C}$ e $28^{\circ} \mathrm{C}$ em condições de escuro, por 45 dias, até o aparecimento da massa calosa.

Para cada condição, foram feitas 10 repetições empregando-se os seguintes meios:

- Meio 1: sais MS (50\%) (SIGMA) (2,15 g/L), acrescidos de tiamina (10 mg/L), piridoxina (3 mg/L), ácido nicotínico (2 mg/L), inositol (99 mg/L), caseína hidrolisada (500 mg/L), glicina (5 mg/ $\mathrm{L})$, cisteína $(250 \mathrm{mg} / \mathrm{L}), \operatorname{PVP}(5 \mathrm{~g} / \mathrm{L})$, sacarose $(60 \mathrm{~g} / \mathrm{L})$, água de $\operatorname{coco}(100 \mathrm{ml} / \mathrm{L}), 2,4-\mathrm{D}(1 ; 2 ; 4 ; 8 \mathrm{mg} / \mathrm{L})$, cinetina $(0,5 \mathrm{mg} / \mathrm{L})$, gelrite $(2,5 \mathrm{mg} / \mathrm{L})$ e $\mathrm{pH} 5,3$ antes da autoclavagem;

- Meio 2: sais N6 (SIGMA) (4 g/L), acrescidos de vitaminas N6 $(1000 \mathrm{x})(1 \mathrm{ml} / \mathrm{L})$, prolina $(2,9 \mathrm{~g} / \mathrm{L})$, mio-inositol $(100 \mathrm{mg} / \mathrm{L})$, sacarose (20 g/L), caseína hidrolisada (100 mg/L), 2,4-D (0; 2; $4 \mathrm{mg} / \mathrm{L})$, ANA $(0 ; 3 ; 5 \mathrm{mg} / \mathrm{L})$, água de coco $(50 \mathrm{ml} / \mathrm{L})$, phytagel $(2,5 \mathrm{~g} / \mathrm{L}) \mathrm{e}$ $\mathrm{pH} 5,8$ antes da autoclavagem. Após a autoclavagem, foi adicionado $\mathrm{AgNO}_{3}(0,85 \mathrm{~g} / 100 \mathrm{~mL})$ e timentin $(300 \mathrm{mg} / \mathrm{L})$;

- Meio 3: igual ao meio anterior suplementado apenas com ANA (3 mg/L);

- Meio 4: sais MS (100\%) (SIGMA) (4,30 g/L), acrescidos de vitaminas LS (1 ml/L), sacarose $(60 \mathrm{~g} / \mathrm{L})$, inositol $(100 \mathrm{mg} / \mathrm{L})$, ANA (1 mM), phytagel (3,0 g/L), pH 5,8 antes da autoclavagem.

\section{RESULTADOS E DISCUSSÃO}

Após seis semanas, foram observados calos em segmentos de eixos embrionários no meio 1 , em todas as concentrações de 2,4-D testadas, com ênfase para a região do hipocótilo, constatando-se ser esta a região mais facilmente ativada do eixo embrionário de cupuaçu, apresentando maior calosidade. Explantes cultivados nas concentrações menores de 2,4-D (1 e $2 \mathrm{mg} / \mathrm{L})$ apresentaram calos com aspecto branco e brilhante (Figura 1A, B), enquanto aqueles cultivados nas maiores concentrações (4 e $8 \mathrm{mg} / \mathrm{L}$ ) apresentaram um aumento distinto de tamanho, boa formação de calos brancos, com partes amareladas, aspecto gelatinoso, que secaram após alguns subcultivos (Figura 1C, D). Janick (1988) afirmou que altas concentrações de 2,4-D mais água de coco estimulam a produção de calo e anulam a indução de embrião.

Para segmentos cotiledonares, nas concentrações menores de 2,4-D, os explantes ficaram cobertos por calos grandes, brancos e brilhantes (Figura 2A, B), que ficavam amarelados, enquanto, nas concentrações mais altas (4 e $8 \mathrm{mg}$ / L), houve apenas a formação de massa calosa branca, seguida de escurecimento (Figura 2C, D).

Os calos foram subcultivados a cada 15 dias nestes meios e, após 8 semanas, verificaram-se o escurecimento e a morte dos mesmos em todas as concentrações empregadas, o que poderia ser atribuído à combinação de 2,4-D com água de coco. Estes resultados concordam com os de Kononowicz et al. (1984), empregando embriões zigóticos imaturos de cacau, que observaram escurecimento e morte dos calos, em resposta à combinação de água de coco e 2,4-D acima de $2 \mathrm{mg} / \mathrm{L}$.

$\mathrm{O}$ alto nível de sacarose empregado (6\%), combinado com água de coco, também pode ter deprimido a embriogênese somática de calos em cupuaçuzeiro. Sugerem-se o emprego de concentrações menores de $2,4-\mathrm{D}$ e estudos para verificar qual o melhor nível de sacarose, na presença e ausência de água de coco, no processo embriogênico de Theobroma grandiflorum.

Após seis semanas no meio 2, observaram-se a presença de raiz em segmentos de hipocótilo, no meio sem regulador de crescimento, e calos em segmentos radiculares (Figura 3A, B). Estes efeitos podem ser devidos à presença de água de coco no meio de cultura. Legrand et al. (1984) concluíram que a água de coco favoreceu a rizogênese e calogênese em hipocótilo de 


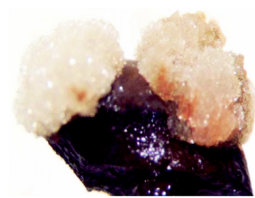

A

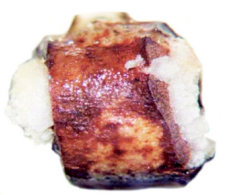

B
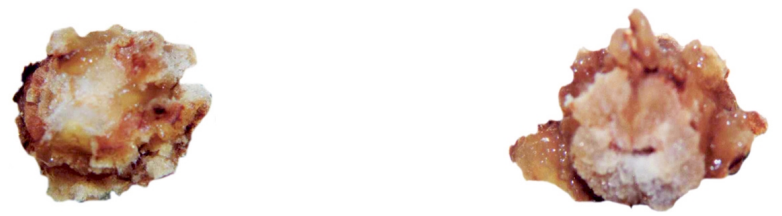

C

D

FIGURA 1 - Calos da região do hipocótilo de eixo embrionário de cupuaçu desenvolvidos em meio com 2,4-D. A) Calos da região do hipocótilo cultivados com 1 $(\mathrm{mg} / \mathrm{L})$ de 2,4-D (barra horizontal $=0,6 \mathrm{~cm}) ; \mathrm{B})$ cultivados com $2(\mathrm{mg} / \mathrm{L})$ de 2,4-D (barra horizontal $=0,7 \mathrm{~cm}) ; \mathrm{C}$ ) cultivados com $4(\mathrm{mg} / \mathrm{L})$ de 2,4-D $($ barra horizontal $=0,4 \mathrm{~cm}) ; \mathrm{D})$ Calos da região do hipocótilo cultivados com 8 (mg/L) de 2,4-D (barra horizontal $=0,6 \mathrm{~cm}$ ).

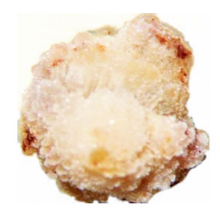

A
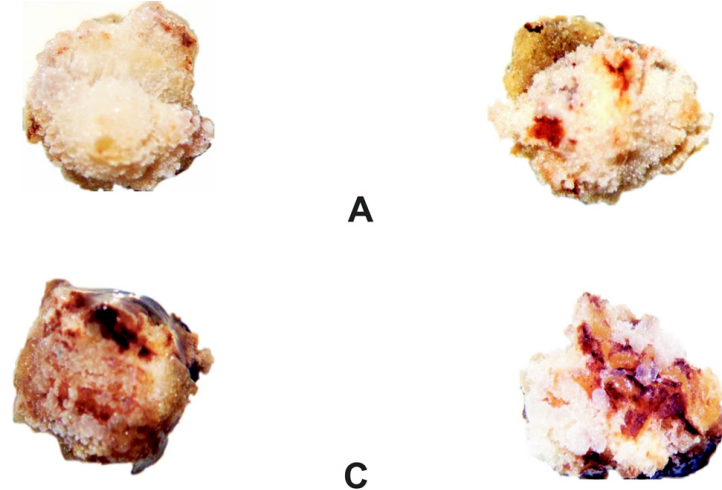

C

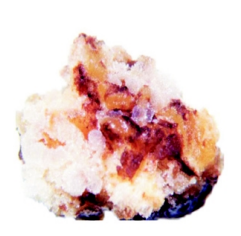

B

FIGURA 2 - Segmentos de cotilédone de cupuaçu desenvolvidos em meio com 2,4-D. A) Segmentos cotiledonares cultivados com 1 (mg/L) de 2,4-D (barra horizontal $=0,6 \mathrm{~cm}$ ); B) Segmentos cotiledonares cultivados com $2(\mathrm{mg} / \mathrm{L})$ de 2,4-D (barra horizontal =0,6 cm); C) Segmentos cotiledonares cultivados com $4(\mathrm{mg} /$ L) de 2,4-D (barra horizontal $=1,1 \mathrm{~cm})$; D) Segmentos cotiledonares cultivados com $8(\mathrm{mg} / \mathrm{L})$ de 2,4-D (barra horizontal $=0,6 \mathrm{~cm}$ ).

plântulas de cacaueiro, com emprego de meio básico, sem regulador de crescimento. Calos brancos friáveis foram observados em todos os outros meios empregados, sendo estes mais pronunciados também na região do hipocótilo. Os meios que continham apenas ANA $(3 ; 5 \mathrm{mg} / \mathrm{L})$ apresentaram o maior número de raízes acompanhados de massa calosa (Figura 3C, D) enquanto os meios que continham ANA e $2,4-\mathrm{D}(3 ; 2 \mathrm{mg} / \mathrm{L})$ apresentaram calos brancos e raízes (Figura 3E). Com cotilédones também houve indução de calos, que escureceram e secaram, não sendo evidenciado nenhum calo embriogênico nestes meios.

Os calos foram subcultivados a cada 15 dias nestes meios e, após um mês, foram transferidos para meio líquido, sem

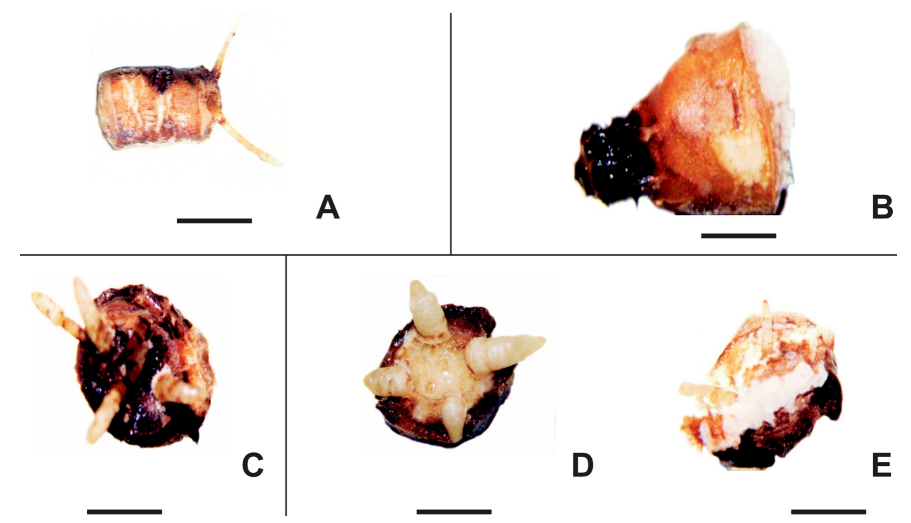

FIGURA 3 - Segmentos de eixo embrionário de cupuaçu cultivados em meio com 2,4-D e ANA. A) Segmento de hipocótilo cultivados em meio sem regulador de crescimento (barra horizontal $=8,0 \mathrm{~cm}$ ); B) Segmento de raiz cultivado em meio sem regulador de crescimento (barra horizontal $=8,0 \mathrm{~cm}$ ); C) Segmento de hipocótilo cultivado em meio contendo ANA $(3 \mathrm{mg} / \mathrm{L})$ (barra horizontal $=7,0 \mathrm{~cm})$; D) Segmento de hipocótilo contendo ANA $(5 \mathrm{mg} /$ L) (barra horizontal $=0,4 \mathrm{~cm}$ ); E) Segmento de hipocótilo contendo ANA e 2,4-D (3; $2 \mathrm{mg} / \mathrm{L}$ ) (barra horizontal $=1,0 \mathrm{~cm})$.
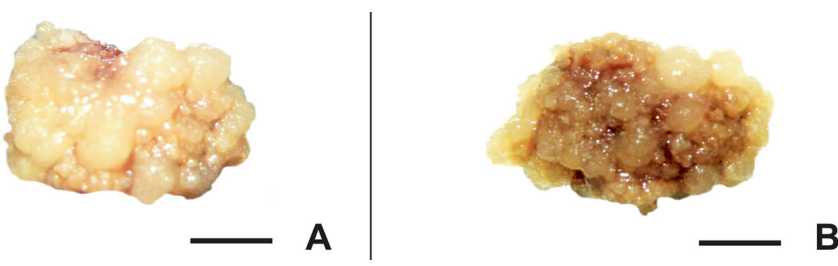

FIGURA 4 - Calos de cupuaçu cultivados em meio com ANA. A, B) Calos friáveis após 3 semanas de cultivo (barra horizontal $=1,2 \mathrm{~cm}$ ).

regulador de crescimento, a fim de estimular o aparecimento de estruturas embriogênicas. Adu-Ampomah et al. (1988) obtiveram de $80 \%$ a $100 \%$ de melhoria no desenvolvimento de embriões somáticos com o emprego de meio líquido. Figueira \& Janick (1993) concluíram que a pré-cultura de embriões somáticos em meio líquido é benéfica para o seu desenvolvimento. Ranch (1993) afirmou que a maturação em meio líquido facilitaria a pronta conversão de maior número de embriões somáticos. Castillo et al. (1998) aumentaram a produtividade de embriões somáticos de Carica papaya L., bem como reduziram o tempo necessário para a maturação do embrião, cultivando calos embriogênicos em meio de maturação líquido.

As culturas foram dispostas em frascos Erlenmeyer, os quais foram mantidos sob agitação contínua em agitador a $120 \mathrm{r}$ / min, intercalando luz e escuro. Após 3 dias nestas condições, observou-se aumento de tamanho dos explantes, bem como escurecimento dos mesmos. As culturas permaneceram 15 dias nestas condições, sendo, em seguida, transferidas para um meio sólido, no caso o meio 3, empregando-se $3 \mathrm{mg} / \mathrm{L}$ de ANA, com o 
objetivo de estimular o aparecimento de estruturas embriogênicas. Apesar do escurecimento dos explantes, 3 semanas após, observou-se o aparecimento de calos amarelos, com aspecto friável (Figura 4A, B). Estes resultados também foram obtidos por Figueira \& Janick (1993), empregando tecido nucelar de cacau como explante.

As culturas foram mantidas nesse meio durante 5 semanas sendo, em seguida, transferidas para um meio de regeneração, o meio 4. As culturas foram subcultivadas a cada 7 dias neste meio e, após um mês, observou-se que os calos permaneceram indiferenciados.

\section{CONCLUSÕES}

1. A região do hipocótilo do eixo embrionário da semente de cupuaçu apresentou maior calosidade.

2. As maiores concentrações de 2,4-D (4 e $8 \mathrm{mg} / \mathrm{L}$ ) promoveram bom desenvolvimento de segmentos de eixos embrionários, acompanhados de calos brancos.

3. O ácido naftaleno acético promoveu o aparecimento de raízes e formação de massa calosa.

4. A combinação de ANA e 2,4-D (3;2 mg/L) promoveu o aparecimento de raízes e calos brancos em segmentos de hipocótilo.

5. A água de coco favoreceu a rizogênese e calogênese em meio sem reguladores.

6. O meio líquido favoreceu o aparecimento de calos friáveis.

\section{REFERÊNCIAS BIBLIOGRÁFICAS}

ADU-AMPOMAH, Y.; NOVAK, F. J.; AFZA, R.; VAN DUREN, M.; PEREA-DALLOS, M. Initiation and growth of somatic embryos of cocoa (Theobroma cacao L.). Café Cacao Thé, Paris, v. 32, n. 3, p. 187-200, 1988.

CALZAVARA, B.B.G.; MULLER, H. M.; KAHWAGE, O M. da C. Fruticultura Tropical: o cupuaçuzeiro, cultivo, beneficiamento e utilização do fruto. Belém: EMBRAPA/CPATU, 1984. p. 1-110. (Documento, 32).

CASTILLO, B.; SMITH, M.A.L.; YADAVA, U.L. Liquid system scale up of Carica papaya L. somatic embryogenesis. Journal of Horticultural Science \& Biotechnology, London, v. 73, n. 3, p. 307-311, 1998.

DAMIÃO FILHO, C. F. Cultura de tecidos de plantas: micropropagação. Jaboticabal: FUNEP, 1995. 25 p.

FIGUEIRA, A.; JANICK, J. Development of nucellar somatic embryos of Theobroma cacao. Acta Horticulturae, Wageningen, n. 336, p. 231-38,1993.

JANICK, J. Embryogenics: the technology of obtaining useful products from the culture of asexual embryos. In: CROCOMO, O. J. (Ed.)b Biotechnology of plants and microorganisms. Ohio: State University Press, 1986. p. 97-117.

JANICK, J.; WHIPKEY, A. Somatic embryogenesis in Theobroma grandiflorum. HortScience, Alexandria, n. 23, p.807, 1988. (Abstract).

KONONOWICZ, H.; KONONOWICZ, A. K.; JANICK, J. Asexual embryogenesis via callus of Theobroma cacao L. Zeitschrift für Pflanzenphysiologie, Stuttgart, v. 113, n. 4, p. 347-358, 1984.

LEGRAND, B.; CILAS, C.; MISSISSO, E. Comportement des tissus de Theobroma cacao L. var. Amelonado cultivés in vitro. Café Cacao Thé, Paris, v. 28, n. 4, p. 245-250, 1984.

PIERIK, R.L.M. In vitro culture of higher plants. Dordrecht: Martinus Nyhoff Publishers, 1987.344 p.

RANCH, P. J. The potential for synthetic soybean seed. In: REDENBAUGH, K. (Ed.) Synseeds: applications of synthetic seeds to crop improvement. Florida: CRC PRESS, 1993. p. 32951.

SINGHA, S. Influence of agar concentration on in vitro shoot proliferation of Malus sp. "Almey"and Pyrus communis "Seckel". Journal of the American Society for Horticultural Science, Alexandria, v. 107, n. 4, p. 657-660, 1982.

VENTURIERI, G. A.; ALVES, M. L. B.; NOGUEIRA, M. Q. O Cultivo do cupuaçuzeiro. Informativo SBF, Itajaí, v. 4, n.1. 1985. 